\title{
Overshadowing of environmental cues by an odor in toxicosis-based conditioning in rats
}

\author{
HARALD TAUKULIS and SHANE ST. GEORGE \\ Sir Wilfred Grenfell College, Memorial University of Newfoundland \\ Corner Brook, Newfoundland, Canada
}

\begin{abstract}
It was demonstrated that an odor presented to rats in a distinctive environment can interfere with toxicosis-based conditioning to the environmental cues. Rats poisoned when they drank unflavored water in a black compartment odorized with oil of eucalyptus exhibited no suppression of water intake when they were subsequently tested in the same compartment minus the odor. In contrast, rats poisoned in the same compartment minus the odor later exhibited reduced water consumption in that environment. Oil of eucalyptus proved to be as effective an overshadowing stimulus as a taste cue (a $1.5 \% \mathrm{NaCl}$ solution).
\end{abstract}

It is generally assumed that rats will quickly and easily learn to associate taste stimuli with toxininduced distress. All other stimuli appear to be inferior to taste in the sense that conditioning is slower and/or weaker (Domjan, 1980; Garcia, Hankins, \& Coil, 1977; Nachman, Rauschenberger, \& Ashe, 1977; Revusky \& Garcia, 1970). Even odor, when it is presented in the absence of a novel taste, acquires conditioned aversive properties less readily (Hankins, Garcia, \& Rusiniak, 1973). The exception to this rule occurs when an odor/taste compound is paired with a toxin. Here, the presence of the taste can bring about a potentiated odor aversion (Palmerino, Rusiniak, \& Garcia, 1980; Rusiniak, Hankins, Garcia, \& Brett, 1979).

It is also generally assumed that, in rats, odortoxicosis associations will develop more readily than associations between so-called exteroceptive stimuli (visual, auditory, tactile, and location cues) and illness (Garcia, McGowan, \& Green, 1972); but this assumption has received scant experimental attention (although see Archer, Sjöden, Nilsson, \& Carter, 1980). Nor has the possibility of odor-exteroceptive cue interactions been considered. It is possible, for example, that the presence of an odor might facilitate toxicosis-based conditioning to exteroceptive cues in the same way that taste has been shown to facilitate conditioning to both odor (Palmerino et al., 1980; Rusiniak et al., 1979) and color (Galef \& Osborne, 1978 ) in rats. Alternatively, an odor might overshadow all but gustatory cues, thereby precluding or limiting any exteroceptive cue-toxicosis associations.

This research was supported, in part, by Grant $\mathbf{A 7 4 7 8}$ from The Natural Sciences and Engineering Research Council of Canada. The authors mailing address is: Department of Psychology, Sir Wilfred Grenfell College, Memorial University, Corner Brook, Newfoundland A2H 6P9, Canada.
The present experiments were designed to explore odor-exteroceptive cue interactions.

\section{EXPERIMENT 1}

In the training phase of Experiment 1, three groups of rats were injected with a toxin, lithium chloride, and then placed into a distinctive compartment (a black wooden box) which provided the relevant exteroceptive cues. Here they were allowed to drink (1) unflavored water, (2) unflavored water in the presence of a strong odor (oil of eucalyptus), or (3) $\mathrm{NaCl}$-flavored water. In the test phase, conditioning to the compartment was measured in terms of the degree to which this environment suppressed water ingestion when odor or taste cues were absent.

\section{Method}

Subjects. The subjects were 24 male Long-Evans rats obtained from Canadian Breeding Farms and Laboratories (St. Constant, Quebec) at a weight range of 50-75 g. They were reared in the authors' laboratory until they averaged $258 \mathrm{~g}(\mathrm{SD}=21.5 \mathrm{~g})$. All were housed in individual, translucent, polypropylene cages (Hazleton HP301) with wire lids. Purina Rat Chow was available at all times, except in the experimental apparatus. Water, when it was provided, was always demineralized. Immediately prior to the training phase of the experiment, the rats were divided into three groups of eight animals each on the basis of their body weights, so that the mean weights for the three groups were 254 , 259 , and $261 \mathrm{~g}$.

Apparatus. The apparatus consisted of two very similar wooden boxes measuring $30.0 \times 12.5 \times 15.0 \mathrm{~cm}(1 \times \mathrm{w} \times \mathrm{h})$; both had wiremesh floor and Plexiglas tops. At one end of each, a $1.3-\mathrm{cm}$ hole accommodated a glass drinking tube that emerged from a bottle clipped to the outside of the box wall. The walls and floor of each box were painted either white or black, and the exterior surface of the Plexiglas top was coated with a matching adhesive vinyl (white or black, respectively). To insure that the boxes smelled the same, they were coated entirely with a clear liquid acrylic (Varathane) and were allowed to air thoroughly before being used so that little of the acrylic odor remained. Each box was housed in a $2.2 \times 1.8 \times$ $2.4 \mathrm{~m}(\mathrm{l} \times \mathrm{w} \times \mathrm{h})$ ventilated cubicle. A cubicle containing a white box was illuminated by a fluorescent light fixture mounted in the 
ceiling, whereas a cubicle containing a black box was only dimly illuminated by a $7-W$ lamp mounted approximately $1 \mathrm{~m}$ from the floor.

Procedure. For 10 consecutive days, all rats were given water for 10 min per day in their home cages in order to accustom them to a drinking schedule.

The training phase lasted 12 days. On Training Days 1 and 2 , each rat was placed into a white box where it was presented with water for 5 min per day. Each of these sessions was followed immediately by 10 -min access to water in the home cage. The white box would never be paired with lithium distress for any animal, and therefore it was given the designation "W-."

During the next 8 days, all rats were given unflavored water in W- two more times, on Treatment Days 3 and 7, for 5 min on each occasion. Five to $6 \mathrm{~h}$ after each session, they were permitted free access to water for $17.5 \mathrm{~h}$ in the home cages. On two other occasions (Treatment Days 5 and 9), each rat was exposed to the black box (designated $\mathrm{B}+$ ) that would be paired with lithium. Immediately prior to being placed into this compartment for $5 \mathrm{~min}$, each animal was injected with $10 \mathrm{ml} / \mathrm{kg}$ of a $.3 \mathrm{M} \mathrm{LiCl}$ solution. Once in B+, one group of rats (Group B-OE) was presented with a drinking spout containing unflavored water. Directly beneath this spout, but under the wire-mesh floor so that the rat could not touch it, an open petri dish was placed containing a $3-\mathrm{cm}^{2}$ piece of filter paper upon which $.2 \mathrm{ml}$ of oil of eucalyptus (OE) had been dropped. A second group (Group B) was also presented with the unflavored water, but the petri dish held only filter paper without the odorant. A third group (Group B-NaCl) was treated exactly like Group B except that the drinking spout contained a $1.5 \% \mathrm{w} / \mathrm{v}$ $\mathrm{NaCl}$ solution instead of unflavored water. Immediately after each drinking session, each animal was returned to its home cage and, 5 to $6 \mathrm{~h}$ later, was provided with $17.5 \mathrm{~h}$ free access to water. On Treatment Days 11 and 12, all animals were given 20 min access to water in their home cages per day.

The duration of the test phase was 7 days. On Test Days 1-6, every animal was allowed to drink unflavored water for $5 \mathrm{~min}$ in one of the two boxes. Immediately after each drinking session, it was permitted access to water for $20 \mathrm{~min}$ in the home cage.

On Test Days 1 and 2, all groups were placed into $W$ - to determine if they would exhibit a generalized aversion to this com. partment. The test of principal interest occurred on Test Day 3. All groups were placed into $B+$, where it was anticipated that they would exhibit varying degrees of suppression of water intake.

Test Days 4-6 were designed to assess the degree of aversion to the oil of eucalyptus that had developed in Group B-OE. All groups were placed into $\mathrm{W}$ - and exposed to $.2 \mathrm{ml}$ of the odorant on filter paper in a petri dish located under the drinking spout.

Test Day 7 was designed to assess the aversion to $\mathrm{NaCl}$ that Group B-NaCl was expected to exhibit. All groups were placed into $\mathrm{W}-$, where they were presented with a $1.5 \% \mathrm{w} / \mathrm{v} \mathrm{NaCl}$ solution rather than the unflavored water of Test Days 1-6.

\section{Results and Discussion}

The mean water intakes for all groups on Test Days 1-6 are shown in Figure 1. The three groups did not differ significantly on Test Day $1[\mathrm{~F}(2,21)=2.45$, $\mathrm{p}>.05]$ or on Test Day $2[\mathrm{~F}(2,21)<1]$, although Group B showed a slight tendency to drink less than the other two groups on Test Day 1. On Test Day 3 (the day of primary interest), the three groups did differ significantly $[F(2,21)=6.13, p<.01]$, with Group B drinking less than either Group B-OE [ $\mathrm{t}(14)$ $=3.32, \mathrm{p}<.01]$ or Group B-NaCl $[\mathrm{t}(14)=2.62, \mathrm{p}<$ .05]. Group B also drank less in B+ on Test Day 3 than it had consumed in $W-$ on Test Day $2[t(7)=$ $2.67, p<.05]$. Neither Group B-OE nor Group B$\mathrm{NaCl}$ exhibited such a difference [both ts $(7)<1]$.

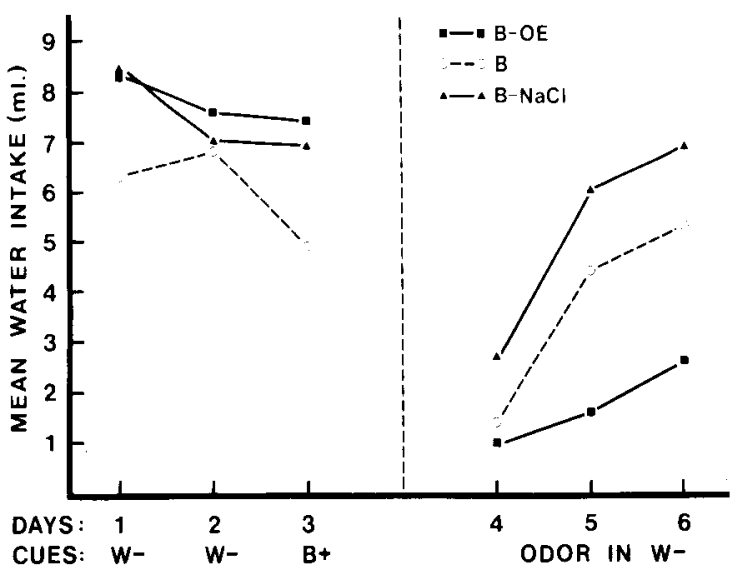

Figure 1. Mean water intake for each of the three groups in Experiment 1 on Test Days 1-6.

On Test Days 4, 5, and 6, Group B-OE exhibited strong suppression of drinking in the presence of the $\mathrm{OE}$ odor, as anticipated. Over the 3 days combined, this group drank less than Group $B[F(1,14)=4.65$, $\mathrm{p}<.05]$ and Group B-NaCl $[\mathrm{F}(1,14)=7.26, \mathrm{p}<.025]$, while the latter two groups did not differ $(F<1)$. Unexpectedly, both Group B and Group B-NaCl exhibited a pronounced neophobia for the odor.

On Test Day $7(\mathrm{NaCl}$ in $\mathrm{W}-)$, mean intakes were as follows: Group B-OE, $7.3 \mathrm{ml}$; Group B, $6.1 \mathrm{ml}$; and Group B-NaCl, .1 ml. As anticipated, Group B$\mathrm{NaCl}$ showed a strong $\mathrm{NaCl}$ aversion relative to Groups B-OE $[\mathrm{t}(14)=8.12, \mathrm{p}<.001]$ and $\mathrm{B}[\mathrm{t}(14)=$ $6.90, \mathrm{p}<.001]$. The latter two groups did not differ $[\mathrm{t}(14)<1]$.

The results from Test Day 3 indicated that both the odor and the taste overshadowed the exteroceptive $\mathrm{B}+$ cues. The overshadowing by taste was expected in light of previous evidence showing a similar effect (Best, Best, \& Mickley, 1973). However, the overshadowing of environmental cues by odor was heretofore an undemonstrated phenomenon, although some investigators have implicitly anticipated this effect when designing their studies. For example, Best et al. (1973) were careful to control for possible discriminable odor cues in the two compartments that they used in their experiments so that they could claim a true toxicosis-based exteroceptive cue discrimination. The present results indicated that their concern was warranted. It appears that rats will associate at least some odors with illness more readily than they will exteroceptive cues; and if two sets of environmental cues include different olfactory components, then toxicosis-based discrimination learning may be facilitated. However, the discrimination may be based upon the odors alone.

The strong neophobia for the odor shown by Groups $\mathrm{B}$ and $\mathrm{B}-\mathrm{NaCl}$ on Test Days 4-6 was surprising. Perhaps this effect can be explained simply in 
terms of an enhancement of neophobia for an odor that may result as a consequence of the animal's previous experience with lithium toxicosis. Carroll, Dinc, Levy, and Smith (1975) showed that the normal neophobia that rats exhibit for a novel flavored solution is enhanced in animals that have had a history of lithium poisoning following water ingestion. While these investigators used a taste stimulus to demonstrate the enhancement effect, it is possible that the phenomenon is applicable to odor as well. The only difficulty with this generalization from the Carroll et al. (1975) study is that, in their experiments, no enhancement of neophobia was found when a period of $48 \mathrm{~h}$ intervened between the $\mathrm{LiCl}$ exposure and the enhancement test. In the present experiment, a total of $144 \mathrm{~h}$ intervened between the rats' last $\mathrm{LiCl}$ experience and their exposure to the novel odor. The difference between the two studies may be explained by the fact that Carroll et al. (1975) gave their animals only one $\mathrm{LiCl}$ exposure, whereas the animals in the present study were given two. The extent to which neophobia is enhanced and the temporal parameters of this effect may vary as a function of the number of occasions on which the animal experiences the lithium distress prior to its initial contact with the taste or odor stimulus.

\section{EXPERIMENT 2}

Experiment 1 demonstrated that an odor presented to rats in a distinctive environment can interfere with toxicosis-based conditioning to the exteroceptive environmental cues. However, even in the absence of the odor (Group B), conditioning to the B+ compartment was weak and therefore likely to be easily disrupted. Experiment 2 was designed to replicate the finding of Experiment 1 while increasing the conditioning to B+. Groups B-OE and B of Experiment 2 were treated exactly like their counterparts in Experiment 1 . The only difference was that they received three pairings of $\mathrm{B}+$ with $\mathrm{LiCl}$ rather than two. In addition, Group $\mathrm{B}-\mathrm{NaCl}$ of Experiment 1 was replaced by Group B-OE-D. This group was treated exactly like Group B-OE (receiving water plus odor in $\mathrm{B}+$ ) except that the lithium injection was administered $60 \mathrm{~min}$ after the animals had drunk in $\mathrm{B}+$ instead of immediately before. The CS-US delay was intended to preclude conditioning to $\mathrm{B}+$, since long-delay environment-illness associations apparently do not develop (Best, Best, \& Henggeler, 1977). Hence, Group B-OE-D's water intake in B+ during the test phase could be used as a baseline against which Group B-OE might be compared. If any conditioning to $\mathrm{B}+$ occurred in Group B-OE, then these animals should drink less water in $B+$ relative to Group B-OE-D.

\section{Method}

Subjects and Apparatus. The subjects were 18 male Long-Evans rats obtained from Canadian Breeding Farm and Laboratories (St. Constant, Quebec) at a weight range of 50-75 g. They were reared in the authors' laboratory until they had attained a mean weight of $221 \mathrm{~g}(\mathrm{SD}=21.0 \mathrm{~g})$ and were housed, fed, and watered as in Experiment 1. Immediately prior to the training phase of the experiment, the animals were divided into three groups of six animals each on the basis of their body weights, so that the mean weights for the three groups were 222,217 , and $225 \mathrm{~g}$.

The apparatus consisted of the $\mathrm{W}-$ and $\mathrm{B}+$ boxes of Experiment 1 . These were again housed in light and dark cubicles, as described earlier.

Procedure. For 10 consecutive days, all rats were given water for 10 min per day in their home cages in order to accustom them to a drinking schedule.

The training procedure of Experiment 2 was like that of Experiment 1 in all unspecified ways. The duration of the training phase was 15 days. On Training Days 1-3, each rat was placed into $W-$, where it was allowed to drink unflavored water for $5 \mathrm{~min}$. Immediately thereafter, it was given 10 min of water in its home cage. Every second day for the next 10 days (Treatment Days 4-13), all animals received a 5 -min water presentation in one of the two boxes. Four to $5 \mathrm{~h}$ after each of these sessions, they were given free access to water in their home cages for $17.5 \mathrm{~h}$. On Treatment Days 6 and 10, water drinking took place in $\mathrm{W}$ - and no injections were administered. On Treatment Days 4, 8, and 12, the animals were presented with water in B+. Groups B-OE and B were injected with lithium chloride $(10 \mathrm{ml} / \mathrm{kg}$ of a $.3 \mathrm{M} \mathrm{LiCl}$ solution) immediately prior to each of these three sessions. Animals in Group B-OE-D $(\mathrm{D}=$ delay) were given this injection $60 \mathrm{~min}$ after each session had ended. For Groups B-OE and B-OE-D, $.2 \mathrm{ml}$ of oil of eucalyptus was dropped onto a square of filter paper resting in an open petri dish positioned under the drinking spout in $\mathrm{B}+$. The odorant was omitted for Group B.

On Treatment Days 14 and 15, all rats were allowed water in their home cages for $20 \mathrm{~min}$ per day.

The test procedure for Experiment 2 was like that of Experiment 1 in all unspecified ways. On each test day, all groups were placed into either W- (Test Days 1-2 and 4-6) or B+ (Test Day 3) and were presented with unflavored water for $5 \mathrm{~min}$. On Test Days 1-3, the OE odor was not present for any animal; and on Test Days 4-6, the OE odor was present in $\mathrm{W}$ - for all animals. Immediately after each of the six drinking sessions, the rats were permitted access to water for $20 \mathrm{~min}$ in their home cages.

\section{Results and Discussion}

The results of Experiment 2 are presented in Figure 2; the mean water intake for each group on each of the 6 test days is shown.

The data of primary interest are those from Test Day 3, when all rats received unflavored, unodorized water in $\mathrm{B}+$. The three groups differed significantly $[F(2,15)=11.78, p<.001]$, indicating that the essential finding of Experiment 1 was replicated: the $O E$ odor interfered with conditioning to $\mathrm{B}+$ in Group B-OE. Pairwise comparisons revealed that Group B drank less than either Group B-OE $[\mathrm{t}(10)=$ $3.59, \mathrm{p}<.01]$ or Group B-OE-D $[\mathrm{t}(10)=4.65$, $\mathrm{p}<$ $.001]$, whereas the latter two groups did not differ from one another $[p>.20]$. Comparison (via paired $t$ tests) of Test Day $3(\mathrm{~B}+)$ water intake with Test Day $2(W-)$ intake showed that Groups B-OE and B-OE-D drank equivalent amounts in both $\mathrm{B}+$ and W- (ps $>.20)$, but Group B drank less on Test 


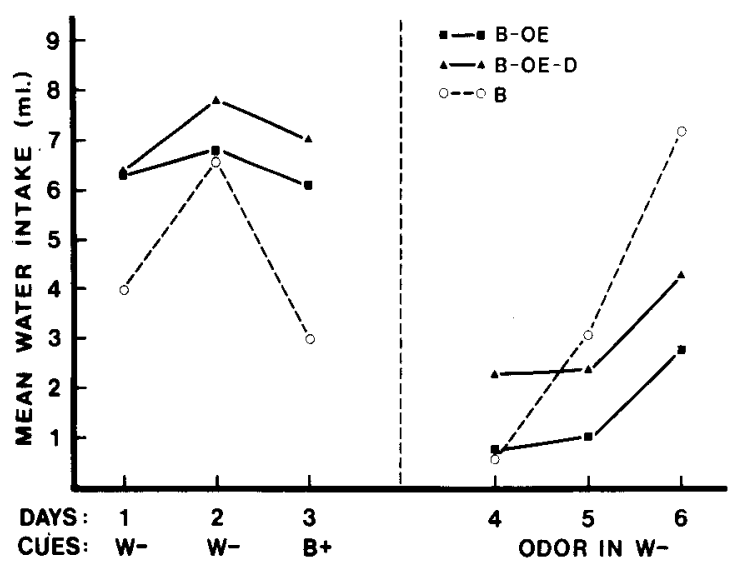

Figure 2. Mean water intake for each of the three groups in Experiment 2 on Test Days 1-6.

Day 3 than it had on Test Day $2[\mathrm{t}(5)=4.23$, $\mathrm{p}<$ .01]. Water intake among the three groups did not differ on Test Day $2[\mathrm{~F}(2,15)<1]$ but did differ on Test Day $1[F(2,15)=3.77, p<.05]$. The latter result appeared to reflect a generalized suppression of water intake in W- by Group B on the first test day. It did not reflect a general tendency for Group B to drink less fluid than the other two groups. An analysis of water consumption in the home cages on the day immediately prior to Test Day 1 revealed no significant differences $[F(2,15)<1]$.

A $3 \times 3$ (groups $\times$ days) ANOVA performed on the water intake from Test Days 4-6 yielded no groups effect $[F(2,15)=2.66, p>.10]$, but did yield a significant days effect $[F(2,30)=33.61, p<.001]$ and a groups $\times$ days interaction $[F(4,30)=5.66, p<.0025]$. This interaction resulted from a strong neophobia to $\mathrm{OE}$ in $\mathrm{W}-$ shown by Group B on Test Day 4, a neophobia that seemed to disappear entirely by Test Day 6. An independent $2 \times 3$ ANOVA comparing Groups B-OE and B-OE-D showed that these groups did not differ significantly in their overall water intakes across Test Days 4-6 $[F(1,10)=1.99, \mathrm{p}>.10]$. Only the days factor proved significant $[F(2,20)=$ $8.07, p<.005$ ], indicating that the odor aversion began to extinguish across trials.

The increase in $B+$ training trials from two to three had the desired effect of strengthening the conditioning to the B+ cues in Group B (compare Figures 1 and 2). However, it also increased this group's tendency to generalize to $\mathrm{W}-$. This generalization is understandable, since $W$ - had many features in common with $\mathrm{B}+$. However, the capacity of $\mathrm{W}-$ to suppress water intake seemed to have disappeared by Test Day 2. When the B+ cues were introduced on Test Day 3, water intake again fell in Group B, demonstrating that some conditioning had accrued to the cues that were specific to the B+ compartment. Curiously, this group also showed a strong neophobia for the $\mathrm{OE}$ odor in $\mathrm{W}$ - on the following days. It will be recalled that a similar effect had appeared in Experiment 1.

Despite the addition of a third conditioning trial, Group B-OE showed no signs of conditioning to B+. This group did not differ from Group B-OE-D, in in which no association between $\mathrm{B}+$ and lithium distress was expected due to the CS-US delay. Furthermore, both groups displayed statistically equivalent odor aversions (Test Days 4-6), indicating that the 60-min delay in Group B-OE-D had not substantially retarded the development of an odor-toxicosis association even though some retardation had been expected (Taukulis, 1974). This might be explained by the fact that oil of eucalyptus is a strong odorant, one that may have had a lingering irritant effect on the nasal mucosae of the rats. This factor could have bridged the temporal gap between the odor and lithium distress, thus eliminating much of the deleterious effect of the delay.

\section{GENERAL DISCUSSION}

The above experiments demonstrated that, when a strong odor and a distinctive environment are paired with lithium toxicosis, the odor will interfere with rather than facilitate conditioning to the environmental cues. Caution must be taken, however, against generalizing too readily from these findings to all odor-exteroceptive cue interactions. For example, it is possible that quite different results would have been obtained had a weaker odorant been used. Moreover, overshadowing by odor might not have occurred had exteroceptive stimuli other than diffuse environmental cues been employed. Galef and Dalrymple (1981) have shown that the more foodrelated an exteroceptive (visual) cue is, the more readily rats will associate that cue with toxicosis. Specifically, they demonstrated that rats will learn to avoid a visually novel food more easily than they will learn to avoid either a visually novel food bin or a visually novel feeding chamber. The "visual novelty" of the food was provided by the color of gelatin capsules into which the food was placed. Had such a food-related exteroceptive stimulus been employed in the present experiments, then facilitation of conditioning might have resulted when the OE odor cue was present on lithium trials. This possibility deserves further investigation.

A phenomenon observed in the latter portion of the test phase in both Experiments 1 and 2 is worthy of note. This is the strong neophobia exhibited by all groups that had not experienced the OE odor prior to testing. It might prove worthwhile to see if this is indeed an "enhanced neophobia" akin to that shown by Carroll et al. (1975) and Domjan (1977) for taste stimuli in rats. The parameters of this phenomenon for odors may be quite different from those for tastes, and a study of these parameters may help to 
elucidate the differences between these types of stimuli as they are used by rats in their regulation of food intake.

\section{REFERENCES}

Archer, T., Suöden, P., Nilsson, L., \& Carter, N. Exteroceptive context in taste-aversion conditioning and extinction: Odour, cage, and bottle stimuli. Quarterly Journal of Experimental Psychology, 1980, 32, 197-214.

Best, P. J., Best, M. R., \& Hengaeler, S. The contribution of environmental non-ingestive cues in conditioning with aversive internal consequences. In L. M. Barker, M. R. Best, \& M. Domjan (Eds.), Learning mechanisms in food selection. Waco, Texas: Baylor University Press, 1977.

Best, P. J., Best, M. R., \& Mickley, G. A. Conditioned aversion to distinct environmental stimuli resulting from gastrointestinal distress. Journal of Comparative and Physiological Psychology, 1973, 85, 250-257.

Carroll, M. E., Dinc, H. I., Levy, C. J., \& Smith, J. C. Demonstrations of neophobia and enhanced neophobia in the albino rat. Journal of Comparative and Physiological Psychology, $1975,89,457-467$.

Domjan, M. Attenuation and enhancement of neophobia for edible substances. In L. M. Barker, M. R. Best, \& M. Domjan (Eds.), Learning mechanisms in food selection. Waco, Texas: Baylor University Press, 1977.

DomJan, M. Ingestional aversion learning: Unique and general processes. In J. S. Rosenblatt, R. A. Hinde, C. Beer, \& M. Busnel (Eds.), Advances in the study of behavior (Vol. 11). New York: Academic Press, 1980.

Galef, B. G., JR., \& Dalnymple, A. J. Toxicosis-based aversions to visual cues in rats: $A$ test of the Testa and Ternes hypothesis. Animal Learning \& Behavior, 1981, 9, 332-334.
Galef, B. G., Jr., \& Osborne, B. Novel taste facilitation of the association of visual cues with toxicosis in rats. Journal of Comparative and Physiological Psychology, 1978, 92, 907-916.

Garcia, J., Hankins, W. G., \& CoIL, J. D. Koalas, men, and other conditioned gastronomes. In N. W. Milgram, L. Krames, \& T. M. Alloway (Eds.), Food aversion learning. New York: Plenum Press, 1977.

Garcia, J., McGowan, B. K., \& Green, K. F. Biological constraints on conditioning. In A. H. Black \& W. F. Prokasy (Eds.), Classical conditioning II: Current research and theory. New York: Appleton-Century-Crofts, 1972.

Hankins, W. G., Garcia, J., \& Rusiniak, K. W. Dissociation of odor and taste in bait shyness. Behavioral Biology, $1973,8,407-419$.

Nachman, M., Rauschenberger, J., \& Ashe, J. H. Stimulus characteristics in food aversion learning. In N. W. Milgram, L. Krames, \& T. M. Alloway (Eds.), Food aversion learning. New York: Plenum Press, 1977.

Palmerino, C. C., Rusiniak, K. W., \& Garcia, J. Flavorillness aversions: The roles of odor and taste in memory for poison. Science, 1980, 208, 753-755.

REvusKy, S. H., \& Garcia, J. Learned associations over long delays. In G. H. Bower \& J. T. Spence (Eds.), Psychology of learning and motivation: Advances in research and theory (Vol. 4). New York: Academic Press, 1970.

Rusiniak, K. W., Hankins, W. G., Garcia, J., \& Brett, L. P. Flavor-illness aversions: Potentiation of odor by taste in rats. Behavioral and Neural Biology, 1979, 25, 1-17.

Taukulis, H. K. Odor aversions produced over long CS-US delays. Behavioral Biology, 1974, 10, 505-510.

(Manuscript received December 2, 1981; revision accepted for publication April 6, 1982.) 